\title{
Adoption of short-term mechanical circulatory support as a viable rescue effort for patients with refractory cardiogenic shock
}

\author{
Charles C. Canver, MD, MBA
}

From Cardiovascular and Thoracic Surgery, Lake Regional Health System, Osage Beach, Mo

Disclosures: Author has nothing to disclose with regard to commercial support.

Received for publication Nov 7, 2016; accepted for publication Nov 8, 2016; available ahead of print Dec 7, 2106

Address for reprints: Charles C. Canver, MD, MBA, Lake Regional Health System, 54 Hospital Drive, Suite 225,

Osage Beach, MO 65065 (E-mail: ccanver@lakeregional.com).

J Thorac Cardiovasc Surg 2017;153:763-4

0022-5223/\$36.00

Copyright (C) 2016 by The American Association for Thoracic Surgery

http://dx.doi.org/10.1016/j.jtcvs.2016.11.025

In the article by Yoshioka and colleagues, ${ }^{1}$ the authors report their more than a decade-long evolutionary experience in selecting the optimal mechanical circulatory support device for patients with acute refractory cardiogenic shock. Their report definitely has practical information for the providers of heart failure care who frequently face the challenge of taking care of these patients.

With its undesirable mortality and morbidity due to multisystem organ ischemia, refractory cardiogenic shock has been a high priority for care providers who primarily treat patients with end-stage heart disease. Although patients with structural heart disease or who are postcardiotomy are the leading causes of refractory cardiogenic shock, noncardiac circulatory failure causing organ ischemia is also frequently encountered. Mainstay treatment of highly fatal refractory cardiogenic shock includes correction of the underlying structural pathology when possible, ventilator support, ionotropic infusion(s) with or without the use of intra-aortic balloon counter pulsation, and continuous renal replacement therapy. When these measures are ineffective to restore the hemodynamic stability with adequate mean arterial pressure, oxygenation, urine output, and tissue perfusion, mechanical circulatory support is the only viable survival option at present.

The use of adult extracorporeal membrane oxygenation (ECMO) has not been readily embraced by most of the cardiac surgical centers. This was primarily due to poor outcomes $^{2}$ reported for the adult population in addition to its high cost due to labor and resource-intensive technological needs. Low numbers of ECMO use by each center have also made intense education and hands-on training mandatory for improved results. Hence, most capable centers have adopted to transfer out such sick patients to their nearby tertiary care centers. However, it is important to note that most patients do not die as a direct consequence of the ECMO device itself, rather it is associated

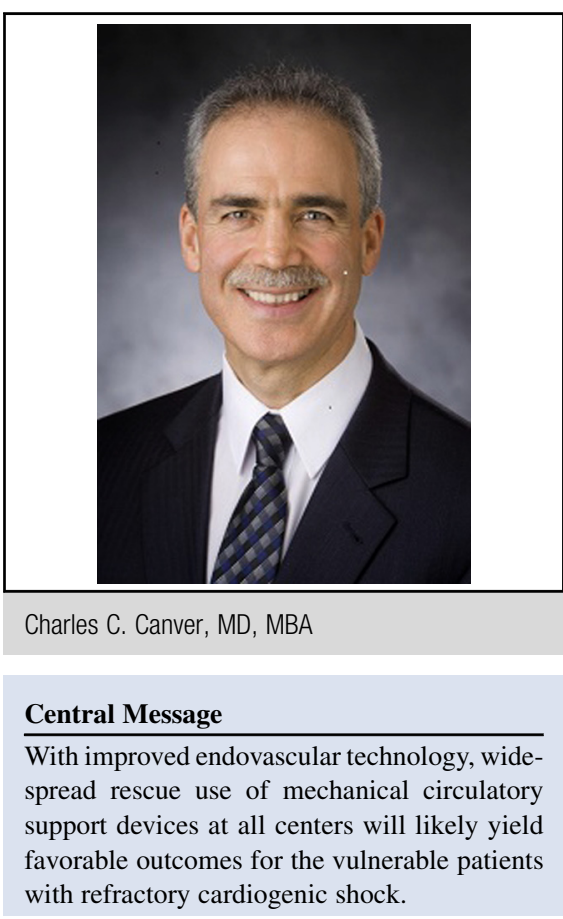

See Article page 752 .

complications, such as hemorrhage, renal failure, infections, acute respiratory distress with hypoxia, and thromboembolic cerebral events that set the stage for the high death rate. It is clear that beginning ECMO support before any irreversible end-organ dysfunction develops and initiating all the efforts to avoid any complications would yield the highest possible survival.

It is now the time for all cardiac centers with reasonable cardiac care experience to embrace the short-term mechanical support as a feasible rescue effort for patients who are about to die without this intervention. The use of peripheral mechanical support devices, including ECMO, is not complicated. Once refractory cardiogenic shock has settled in, ECMO or peripheral mechanical support devices can be promptly placed at any center. There are no absolute contraindications for unexpectedly decompensated patients with refractory cardiogenic shock who are unresponsive to other means of support. As described in the article by Yoshioka and colleagues, ${ }^{1}$ ECMO and peripheral mechanical circulatory support devices can now be 
effectively used at every center as a bridge to decision, to recovery, or to transfer out. Conversion of short-term mechanical circulatory devices and ECMO to long-term support devices (such as ventricular assist devices or total artificial hearts) and/or heart transplantation should still be done at designated centers.

\section{References}

1. Yoshioka D, Takayama H, Garan AR, Topkara VK, Han J, Li B, et al. Bridge to durable left ventricular assist device for refractory cardiogenic shock. J Thorac Cardiovasc Surg. 2017;153:752-62.

2. Sajjad M, Osman A, Mohsen S, Alanazi M, Ugurlucan M, Canver CC Extracorporeal membrane oxygenation in adults: experience from the Middle East. Asian Cardiovasc Thorac Ann. 2013;21:521-7. 